\title{
TRANSCULTURAÇÃO NARRATIVA NO CONTO ROSEANO A MENINA DE LÁ: DIÁLOGO ENTRE CULTURAS E POETIZAÇÃO DAS VOZES ABAFADAS
}

\author{
Ana Luiza Azevedo Fireman
}

$(*)$

\section{Introdução}

Nos últimos anos tem sido comum, efetivamente. a afirmação da imanência como único horizonte legitimo da critica: esta se realizaria na minuciosa descrição interior da obra literária e na revelação de sua estrutura intrinseca, à margem de qualquer projeção que exceda os limites objetivos do texto, e também à margem de qualquer julgamento acerca de sua formulação estética, seu sentido ou sua funcionalidade social.

Cornejo Polar

Nos últimos anos, a crítica literária tem passado por um processo de intensa auto-reflexão e reavaliação de sua função. Dentro desse processo, muitas questões foram suscitadas, mas acreditamos ser a mais relevante a posição de que as obras literárias são signos e remetem a categorias que estão acima de uma estrutura estética: o homem e a sociedade. A função da crítica passa a ser, então, a de revelar as imagens que a obra literária capta do universo humanointerior ou exterior- e representa na forma poética. Não faz sentido fazer crítica literária sem atravessar a ponte que existe entre a obra e o universo social e cultural em que ela está inserida, como também não nos cabe construir essa ponte, pois ela já existe e se insere nos alıcerces da obra. A nossa função é somente atravessá-la e apontar o caminho aos leitores, quando defendemos, como o fez a epígrafe do crítico Cornejo Polar (2000:22), uma crítica não imanente da obra de arte.

Esse compromisso, o de atravessar a ponte entre a obra literária e o sócio-cultural, torna-se ainda mais urgente quando se trata do contexto latino-americano, já que esse continente passa por uma fase de intensa tentativa de auto-interpretação. A necessidade de auto-

(") Mestranda em Letras, UFAL. 
interpretação nasce de uma consciência verdadeiramente americana, do reconhecimento e da aceitação, sem complexos ou culpas, de nossa pluralidade social e cultural, de nossas diversidades e assimetrias internas.

Nesse sentido, são de suma importância estudos críticos que se propõem a "atravessar pontes", a revelar imagens captadas e representadas na obra literária, a ouvir atentamente o diálogo que o texto poético estabelece com o mundo. Acreditamos que os estudos literários comprometidos com as categorias culturais cumprem sua função de revelar as imagens representadas no texto, viabilizando o processo de auto-interpretação pelo qual passa o continente latinoamericano.

Abraçando os questionamentos suscitados acima, pretendemos nos debruçar sobre o conto $A$ menina de lá, do escritor mineiro Guimarães Rosa, para revelar as imagens dos estratos culturais representados poeticamente e "ouvir o diálogo" que o texto estabelece com as tradições. Para isso, utilizaremos o conceito de transculturação narrativa, do crítico uruguaio Angel Rama (1975), categoria criada para representar os graus captados na relação entre os escritores transcultadores e suas culturas, materializadas nas obras artisticas.

\section{AMERICANidade E TransCUlturaÇão}

\subsection{A humanidade é plural}

Os tempos atuais estão impregnados pelas noções de diferença, de pluralidade, de ruptura e de descontinuidade. Segundo Américo Pessanha (1987:61),
enquanto em outros momentos culturais insistiu-se sobretudo nas noçōes de continuidade e unicidade, hoje, como um dos traços caracteristicos do pensamento contemporâneo, prevalecem as categorias de multiplicidade, de ruptura, de alteridade.

Esse deslocamento de uma concepção monista e redutora para uma concepção multifacetada é resultante da consciência que hoje temos da impossibilidade de se instituir um único ponto de vista, fixo e definitivo, e da relativização das "verdades absolutas": teológicas, científicas, éticas e estéticas. Essa consciência das diferenças, por sua 
vez, é resultante em parte da contribuição da Antropologia, pois. graças a ela, sabemos hoje que são muitas as possibilidades de ser, de estar no mundo, de se expressar por meio das diversas linguagens $\mathrm{e}$ culturas,

o que aponta um humano "multifacetado", distante de padrões unitários e universais que antes propunham como paradigma um caso particular de humanidade: o branco. europeu, civilizado (Pessanha, 1987:64).

As reflexões sobre alteridade trazidas pela Antropologia- e mais ainda a sua experiência- levam-nos a refletir sobre o outro cultural, categoria de dificil apreensão, pois temos dificuldade de fixar nossa atenção no que não nos é habitual, familiar, cotidiano: o olhar sobre o outro passa a ser também um olhar sobre nós mesmos. Dessa forma, reconhecemos que "somos uma cultura possível entre tantas outras, mas não a única" (Laplantine,1998:21). Ou seja, "o projeto antropológico consiste, portanto, no reconhecimento, conhecimento. juntamente com a compreensão de uma humanidade plural" (Laplantine, 1998:22).

\subsection{A América e sua pluralidade}

A consciência da diversidade e da pluralidade humana, através da experiência da alteridade, contribuiu para uma maior aceitação da intensa multiplicidade cultural que compõe a América Latina e sobretudo para uma valorização dessa multiplicidade: o que antes parecia disformidade e atraso passa a ser sinônimo de contemporaneidade.

Cornejo Polar nos lembra que no caso da América Latina não se trata de uma comunidade homogênea nem de uma nação com múltiplas etnias, mas de um continente de imensa diversidade. o que aumenta notavelmente a pretensão de legitimidade (Valdés, 2000:07).

Como acreditavam os escritores modernistas Mário e Oswald de Andrade, a heterogeneidade multicultural não constituia um fator negativo ou algo que precise ser eliminado, mas ao contrário, é algo que deve ser legitimado: marca peculiar sem a qual seria impossivel qualquer tentativa de compreensão histórica, social e cultural da América Latina. 
Para entender essa multiplicidade cultural latino-americana é necessário perceber que a colonização européia não eliminou as tradições das culturas autóctones, "ela deu lugar a formas sincréticas e híbridas, onde as matrizes indígenas, africanas e européias foram reelaboradas e ressignificadas para constituir uma mistura" (Bernd,1999:22). Essa concepção substitui a idéia de aculturação, processo em que se elimina uma determinada cultura e se assimila outra, o que poderia ser comparado a um gesto simples como tirar uma camisa e vestir outra. Para Fernando Ortiz, a idéia de transculturação

expressa melhor as diferentes fases do processo transitivo de uma cultura para outra, porque esse processo não consiste apenas em adquirir uma cultura, que é o que, a rigor, indica a palavra aculturação, mas, ao contrário, o processo implica também na perda ou no derraizamento da cultura precedente, o que poderia ser considerado como uma parcial desculturação, e ,além disso, significa a conseguinte criação de novos fenômenos culturais que poderiam ser denominados de neoculturação (Rama,1975:74).

Se antes se acreditava que a civilização européia dissolveu as culturas indígena e africana e que, por isso, a América constituía um bloco homogêneo e uniforme, hoje temos consciência de que o processo transitivo de uma cultura para outra consiste em uma complexa ressignificação dos fenômenos, viabilizada pela dialética da perda e da troca cultural e pelo surgimento do novo: o híbrido.

Tendo consciência da singular heterogeneidade que impregna o "multiverso" latino-americano, devemos ter o cuidado em não simplificar as formas sincréticas vendo-as como um fenômeno harmônico e linear. Ou seja, não podemos conceber o mosaico que constitui a América Latina como sendo um encontro, um diálogo harmonioso entre diversas culturas- como aponta o senso comum- e, sim, como sendo um diálogo tenso, marcado essencialmente pela contradição e, muitas vezes, pelo desentendimento: lugar de conflito e constante recomeço. É nesse sentido que podemos compreender o fenômeno do estranhamento interno, em que o "estranho" deixa de ser somente o que nos é exterior, mas também o que nos é interior, o que nos pertence. Em outras palavras, os diversos estratos culturais internos da América Latina permanecem em constante estado de choque e de estranhamento, marcados pela contradição e pela concórdia, pelo isolamento e pelo entrelaçamento, alimentando um 
diálogo tenso, conflituoso, e promovendo um processo sempre inacabado, sem previsibilidades ou destino único. Sublinha-se a importância do estudo dos fatores sociais. como desigualdade e luta entre classes, para compreender esse fenomeno do estranhamento entre os diversos estratos internos onde, inclusive, há uma hierarquização injusta desses extratos.

\subsection{Transculturação narrativa}

Para Rama (1975:73), desse processo, vivenciado pelos escritores, de constante reconsideração de uma cultura no diálogo tenso com as outras, internas ou não, surgem três tipos de respostas possiveis: a) "rigidez cultural", em que o intelectual abraça sua cultura recusando qualquer nova contribuição; b) a "vulnerabilidade cultural", em que abraça a cultura do outro renunciando a sua própria e c) a "plasticidade cultural", categoria que integra a tradição e o novo, em que o escritor considerado transculturador dialoga com a cultura do outro, não renunciando à sua. A "plasticidade cultural" é a resposta mais frutifera, pois é baseada na concepção de uma identidade que dialoga com a alteridade; de um "eu" que se afirma sem a exclusão do "outro", diminuindo o risco de se cair numa visão etnocêntrica e redutora das culturas.

É importante ressaltar que para Rama essa "plasticidade cultural" é compreendida como transculturação narrativa quando nào há un sincretismo por mera justaposição de culturas diversas, mas quando a

incorporação de novos elementos de procedência externa deve ser alcançada mediante uma rearticulação total da estrutura cultural propria, indo buscar novos enfoques dentro de sua própria herança (Rama,1975:73).

Sendo assim. não podemos conceber a transculturação narrativa como sendo um simples encontro ou troca entre culturas. mas como algo complexo. resultado de uma total rearticulação e ressignificaçào das culturas, num processo de construção incessante e intensa, e de desconstrução e (des)contunuidade.

Dentro do contexto latino-americano, de estranhamento e entrelaçamento entre os diversos estratos internos, ocupam um capítulo importante os "conflitos das sociedades regionais face à 
modernização que se incorpora através das cidades e portos, que se proclamava transmissora do progresso e que é operada pelas elites dirigentes urbanas" (Rama,1975:77). Os regionalistas respondem a esse conflito quando tentam evitar a ruptura que se avizinha entre os diferentes setores internos, criando pontes indispensáveis para resgatar as culturas regionais. São criadores literários que iluminam poeticamente as vozes abafadas pela modernização, pelo sistema capitalista opressor e excludente, são escritores transculturadores que revisam a tradição interna, através de uma resposta "plástica", desenraizando, rearfimando, absorvendo as novidades e ressignificando a tradição no nível simbólico.

Enquanto que no plano real o processo de transculturação"plasticidade cultural"- possui um elevado grau de determinismo, no plano artístico esse processo ocorre em maior grau de liberdade. É o que Rama chama de "capacidade seletiva", ou seja, o escritor tem mais liberdade para selecionar os níveis que pretende rearticular, ou transculturar no plano representativo. Rama reconhece três niveis ${ }^{1}$ :

a) Nivel lingüístico- "Se há uma renúncia visível às línguas e dialetos regionais, há simultaneamente um esforço para recuperá-lo dentro do discurso literário." Esse processo não se limita a um mero "imitar" regional, pois o autor fala de dentro da comunidade lingüística, fazendo uso fluente da linguagem, reelaborando-a poeticamente e iluminando suas especificidades no próprio narrar.

b) Nível da composição literária- Uma das peculiaridades da oralidade é a narração do elemento insólito com naturalidade e espontaneidade, fazendo com que o plano do verossímil possa funcionar "contiguamente ao plano do fantástico, absorvendoo em função referencial." Dessa forma, os transculturadores foram buscar no seio da oralidade os mecanismos capazes de garantir verossimilhança, dentro da composição literária, aos fatos e personagens insólitos, transpondo as barreiras que existem entre o imaginário e o real, pois tudo seriam verdades humanas.

c) Nível do significado- As culturas internas mantêm um contato ativo com as fontes da criação mítica. Através da experiência

Todas as citações abaixo são de Rama (1975). 
do diálogo com essas culturas, os transculturadores "descobriram" o mito. Esses escritores reconheceram e aceitaram as redes analógicas com que tecemos o mito. recuperando as "percepções sensiveis sobre os objetos e suas relações associativas que lhe dão base." É importante ressaltar que o transculturador não faz uma mera representação do elemento mítico no plano poético, mas dialoga ativamente. como as culturas internas o fazem, com o universo da criação mítica. É o próprio processo de criação que é iluminado dentro da tessitura narrativa.

Dessa forma, segundo Rama, os escritores transculturadores dão voz aos estratos internos, focalizando-os no nível simbólico e trazendo esses universos culturais para o interior da composição poética, fazendo-os "conviverem" contiguamente com as culturas dos grandes centros urbanos, sem hierarquização.

\section{TransculturaÇão no Conto $A$ MENINA DE L $A^{2}$}

\section{$3.1 \mathrm{Um}$ breve resumo}

O conto A menina de lá, de Guimarães Rosa, narra a história de uma menina de nome Maria, filha de uma índia "que nunca tirava o terço da mão". Nhinhinha, como era chamada por todos, era uma criança enigmática, absorvida em seu mundo de poucas e obscuras palavras. Os pais não a compreendiam e sequer a alcançavam, tão distante era o mundo da menina: "não se sabiam suas preferências". Um dia, começou a fazer milagres: tudo que desejava, misteriosamente vinha até ela. Quis o arco-íris e choveu. E, assim como seu existir tão indecifrável, a morte de Nhinhinha vem quando ela ainda contava quatro anos.

\subsection{Nhinhinha: metáfora do estranho}

"A menina de lá". Lá onde? Nhinhinha não tinha lugar definido, era móvel, pertencia a qualquer lugar e a lugar nenhum. Com o seu olhar deitado para um sempre distante, com a sua presença quase imperceptível, com a sua linguagem avessa ce us scus pedidos

Rosa, Guimarães. Primeiras estorias. [s.d.]. 
sempre atendidos, Nhinhinha era impenetrável, inatingível, tão próxima e tão longe, onde ninguém chegava. "Ninguém tinha real poder sobre ela", uma criança de apenas quatro anos que ninguém conseguia decifrar os olhos nem os anseios. Que quase não brincava, nem corria. Que "não queria bruxas de pano, brinquedo nenhum, pouco se mexia". Que não parecia ser criança, nem adulta e, ao mesmo tempo, possuía um quê infantil impregnado de uma madura lucidez. Quem era Nhinhinha? De onde ela veio? Ninguém saberia responder. A menina perecia não ser deste mundo, a menina era de lá. E como o escritor configura essa espacialidade inapreensivel? Esse "lá" tão indecifrável quanto a personagem protagonista?

Através de um elemento dêitico -o advérbio "lá"- o autor consegue deslocar o espaço de circulação de Nhinhinha para um lugar indefinido, reiterando o perfil da personagem: inatingivel e indecifrável. "Miúda, cabeçudota e com olhos enormes", a menina é a própria metáfora do estranho: curou a mãe e previu a própria morte. Nhinhinha permanecia horas imóvel no seu tamborete a alimentar silêncio e, de vez em quando, murmurava algo na sua linguagem fragmentada. Uma menina que não pode ser enquadrada entre as realidades reconhecíveis: ela era de "lá". E morava por trás da "Serra do Mim". A escolha do nome do local onde a personagem morava não é aleatória, pois se analisarmos mais detalhadamente, perceberemos que se trata de um pronome pessoal da primeira pessoa: mim. "Por trás da Serra do Mim". Do leitor, ou do narrador? Quem é o referente para o pronome "mim"? Pode ser cada um de nós, ou o próprio narrador. O que importa é que o narrador parece querer dizer que o outro, o que nos é estranho, muitas vezes também nos é familiar e está dentro de nós, ou "por trás da Serra do Mim".

\subsection{Transculturação nos três níveis}

\subsubsection{Nível lingüístico}

() conto A menina de lá possui marcas incontestáveis do antıgo contador de estorias e traços sofisticados do enunciador moderno, havendo uma apropriação do narrar oral e, ao mesmo cmpo, das contribuições da linguagem letrada:

Em geral, porém, Nhinhinha, com seus nem quatro anos, não incomodava ninguém, e não se fazia notada, a não ser pela perfeita calma, imobilidade e silêncios. (p.22) 
Decidiram de guardar segredos. Não viessem ali os curiosos, gente maldosa e interesseira, com escândalos. (...) O que ao Pai, aos poucos, pegava a aborrecer, era que de tudo não se tirasse o sensato proveito. (p.24)

Nessas citações, percebemos passagens da narrativa em que há marcas da linguagem letrada e, logo em seguida, marcas do narrar oral. Há uma tentativa de resgatar a oralidade em nossa literatura, trazendo-a como elemento interno estruturador: no próprio narrar. Não há um distanciamento entre a fala do narrador, letrada, e a fala do personagem, iletrada, como ocorreu na literatura até o momento do Modernismo. O falar espontâneo do contador de estórias impregna a tessitura narrativa tornando-a híbrida e colorida; não há uma hierarquização entre o narrar oral e a linguagem culta, ambas compõem o texto como elementos internos.

Dessa forma, o falar espontâneo atravessado por marcas da oralidade é iluminado e poetizado, compondo, juntamente com a linguagem letrada, uma nova linguagem: a literária.

\subsubsection{Nível da composição literária}

A personagem Nhinhinha, como já foi dito anteriormente, escapa à nossa realidade palpável; é uma criança indecifrável e cnigmática que faz milagres e adivinha a própria morte. Ou seja, é uma personagem insólita. Mas o narrador tece os fatos com naturalidade, não havendo reações de surpresa, pois tudo é trazido e colocado sob os olhos do leitor de forma bastante espontânea.

Sendo assim, o plano do fantástico adquire, no nível da formulação interna, verossimilhança, absorvendo-a em função referencial convincente. Fatos insólitos são trazidos e tratados como fatos corriqueiros, com simplicidade e naturalidade, sem questionamentos ou inquietações. Como se não houvesse fronteiras rígidas entre realidade e imaginário: tudo são verdades humanas.

Essa naturalidade ao tratar um fato insólito é uma peculiaridade da oralidade, que, muitas vezes, se apropria da forma do depoimento para legitimar a narrativa, garantindo-lhe verossimilhança. Assim, o narrador do conto A menina de lá também dá o seu "depoimento" quando diz ter conhecido Nhinhinha: 
E Nhinhinha gostava de mim. Conversávamos, agora. (...) Outra hora, falava-se de parentes já mortos, ela riu: "vou visitar eles..." Ralhei, dei conselhos, disse que ela estava com a lua. (p.23)

Percebemos, então, que não existe distanciamento entre o narrador e o que ele conta: não é alguém falando sobre o outro. É alguém envolvido com a estória, trazendo a menina de sua própria memória, sendo, portanto, uma estória também do narrador.

\subsubsection{Nível do significado}

As culturas regionais e internas mantêm sempre um contato com as fontes sempre vivas da criação mitica. Os escritores transculturadores "descobriram" o mito e os mecanismos mentais geradores do mito, operação aparentemente sepultada nos seios das culturas cosmopolitas, mas que atualmente tem sido retomada como algo nunca exaurivel.

No conto $A$ menina de lá. Guimarães Rosa mantém um diálogo ativo com a tradição e os mitos da cultura cristã, atualizandoos e ressignificando-os em forma poética. Vários elementos da tradição cristã são flagrados durante a leitura do conto, mas sempre transformados e estilizados.

O nome da personagem protagonista não é uma escolha aleatória: seu nome é Maria, como o da Virgem, a quem tudo rogamos. A menina faz milagres e se chama Maria. Mas, ironicamente, Nhinhinha é irreverente, não atende aos pedidos de seus pars, só faz o que quer: "ninguém tem real poder sobre ela." Não adianta pedir milagres à menina:

Veio a seca, maior, até o brejo ameaçava de se estorricar. Experimentaram pedir a Nhinhinha: que quisesse a chuva. -"Mas não pode, uè..." - ela sacudiu a cabecinha. Instaram-na: que, se não, se acabava tudo, o leite, o arroz, a carne, os doces, frutas, os melados. (...) Dai a duas manhäs quis: queria o arco-iris. Choveu. (p.25)

Daí dizermos que o autor atualiza a tradição, pois a relação mutrinseca que ele estabelece entre a protagonista e Marra. Nossa Senhera. não é uma mera representação: há transformações e molerenclas. 
Outra observação importante é o fato de a menina ser filha de uma mãe india. urucuiana, que só vive com um terço na mão "mesmo quando matando galinhas ou passando descompostura em alguém." Ilá ai um entrecruzamento de culturas e tradições: cristã e indígena. A menina, clue faz milagres e que se chama Maria, é filha de india. Uma india que não tira o terço da mão. O entrecruzamento de culturas e tradiçōes resulta numa forma narrativa híbrida e assimétrica. Essa assimetria é ainda mais acentuada quando os pais, ao descobrirem os dons da fillha,

Decidiram de guardar segredo. Não viessem ali os curiosos, gente maldosa e interesseira, com escândalos. Ou os padres, o bispo, quisessem tomar conta da menina. levá-la para sério convento. (p.42)

Ou seja, apesar de viver com o terço na mão, a mãe de Nhinhinha não descjava que sua filha fosse para um "sério" convento. o cue seria mais provável diante de sua demonstração de religiosidade.

É importante ressaltar também que toda vez que o narrador se refere aos pais de Nhinhinha, as palavras pai e mãe são escritas com as iniciais maiúsculas. Podemos considerar esse fato um diálogo tanbém com a tradição cristã, pois sabemos que faz parte dela esse procedimento:

Ouvia o Pai querendo que a Mãe coasse um café forte, e comentava, se sorrindo: "Menino pidão...menino pidāo..." Costumava também dirigir-se à Māe desse jeito: "Menina grande... (p.23)

Dessa forma, encontramos mais uma ponte entre o conto $A$ menina de lá e a tradição cristã. É importante ressaltar que a relação que o autor estabelece entre o seu texto e essa tradição não é passiva, nào constituindo apenas uma representação ou uma simples alusão. pois o autor atualiza a tradição, juntamente com seus mitos. A partir de sua recriação, traz-lhe novos significados e articula de forma plástica e ativa os elementos internos, compondo um novo tecido: a narrativa literária. 


\subsection{A morte de Nhinhinha: impossibilidade de solução para os conflitos}

Pai e Mãe cochichavam, contentes: que quando ela crescesse e tomasse juízo, ia poder ajudar muita a eles, conforme a Providência decerto prazia que fosse (p.25).

Mas "Nhinhinha adoeceu e morreu”. E qual o significado da morte tão prematura da menina? Será que em um contexto de tantas assimetrias há lugar para alguém capaz de trazer a chuva -mesmo querendo somente o arco-íris- quando a seca ameaça "estorricar" o brejo? O texto parece responder que não.

A nosso ver, a morte de Nhinhinha é a constatação da impossibilidade de uma resolução para os conflitos e contradições representados poeticamente na narrativa. Num universo marcado por tantas assimetrias e incoerências não há lugar para o "sonho", para um "final feliz", onde tudo se resolveria através da "Providência Divina". Dessa forma, o autor representa, no nivel simbólico, a impossibilidade de uma fácil solução para os conflitos internos poetizados em seu
texto.

\section{Conclusão}

O estudo que ora concluímos analisou a relação existente entre categorias culturais formadoras da sociedade brasileira e o conto A menina de lá, de Guimarães Rosa. Buscamos ouvir e interpretar o diálogo que o conto tece com a tradição cristã e a oral. Dessa forma, assumimos uma perspectiva não formalista da relação entre obra literária e contexto cultural.

Como subsidio teórico, utilizamos a Crítica Cultural, sobretudo os conceitos de "transculturação" narrativa do crítico Angel Rama (1975), aliada à Antropologia Cultural. Procuramos apoio antropológico nesse estudo porque a Antropologia Cultural se debruçou desde a sua origem até a contemporaneidade sobre questões fundamentais como identidade, alteridade, tradição, cultura, simbologia e o sagrado.

Acreditamos que o texto literário é inesgotável e, por isso, temos consciência de que o presente estudo é somente uma possibilidade de leitura entre tantas outras. Mas acreditamos também 
que estudos como este possibilitam uma melhor compreensão dos fenomenos culturais que atuam no contexto brasileiro, marcado por pluralidades e diversidades.

Percebemos, no decorrer do estudo, que o autor do conto $A$ menina de lá é um escritor transculturador que ilumina poeticamente o narrar oral, revisando a tradição, representado-a e ressignificando-a no nivel simbólico. Percebemos que Guimarães Rosa mantém um diálogo plástico e ativo com a cultura oral, e que ele tenta responder aos conflitos dos estratos internos frente à modernização, criando pontes para resgatar essas culturas no plano simbólico. Essa representação focaliza e dá voz aos estratos internos, quando os põe, lado a lado, compondo a tessitura narrativa, sem hierarquizações. Ao mesmo tempo em que contribui para o processo de auto-interpretação, pelo qual atravessa o contexto latino-americano quando aponta, no nível simbólico, suas contradições e assimetrias internas, revelando, assim, a pluralidade social e cultural que compõe este continente. Daí a importância de a crítica literária revelar as imagens captadas e representadas na obra de arte, de "atravessar pontes" e apontar caminhos.

\section{REFERÊNCIAS BIBLIOGRÁFICAS}

ARAÚJO, Vera Lúcia Romariz Correia. Identidade e Alteridade Cultural no romance luanda Beira Bahia, de Adonias Filho. Dissertação de mestrado. Maceió: UFAL, 1990.

BERND, Zilá, Lopes Cícero (orgs.). Identidades e estéticas compósitas. Canoas/Porto Alegre/PPG Letras UFRGS: 1999.

CANDIDO, Antonio. Literatura e Sociedade: estudos de teoria e história literária. 8. ed. São Paulo: T.A. Queiroz, 2000.

CORNEJO-POLAR. Antonio. Problemas e perspectivas da literatura latino-americana: O condor voa. Belo Horizonte: UFMG, 2000.

(iliLRTZ, Clifford. A interpretação da cultura. Rio de Janeiro: Guanabara, 1989.

I.APLANTINE, François. Aprender Antropologia. São Paulo: Editora Brasiliense, 1998. 
PESSANHA, José Américo Motta. Cultura brasileira - Tradição Contradição. Rio de Janeiro: Zahar, 1987. Cultura como ruptura.

PIZARRO, Ana (org.). América Latina, Palavra, Literatura e Cultura. vol. 1, edição bilíngüe. São Paulo: Memorial da América latina/ Campinas: UNICAMP, 1993. Palabra, literatura y cultura en las formaciones discursivas coloniales.

RAMA, Ángel. Transculturação na narrativa latino-americana. Cadernos de opinião. Rio de Janeiro, n. 2, p. 71-78, 1975.

ROSA, Guimarães. Primeiras estórias. 41. ed. Rio de Janeiro: Nova Fronteira, [s.d.] 